\title{
Long-term durum wheat monoculture: modelling and future projection
}

\author{
Ettore Bernardoni, ${ }^{1}$ Marco Acutis, ${ }^{1}$ Domenico Ventrella ${ }^{2}$ \\ ${ }^{1}$ Dipartimento di Produzione Vegetale, Università di Milano; ${ }^{2}$ Consiglio per la Ricerca e la sperimen- \\ tazione in Agricoltura - Unità di ricerca per i Sistemi Colturali degli Ambienti caldo-aridi (CRA- \\ SCA), Bari, Italy
}

\begin{abstract}
The potential effects of future climate change on grain production of a winter durum wheat cropping system were investigated. Based on future climate change projections, derived from a statistical downscaling process applied to the HadCM3 general circulation model and referred to two scenarios (A2 and B1) from the Intergovernmental Panel on Climate Change (IPCC), the response on yield and aboveground biomass (AGB) and the variation in total organic carbon (TOC) were explored. The software used in this work is an hybrid dynamic simulation model able to simulate, under different pedoclimatic conditions, the processes involved in cropping system such as crop growth and development, water and nitrogen balance. It implements different approaches in order to ensure accurate simulation of the main process related to soil-crop-atmosphere continuum.The model was calibrated using soil data, crop yield, AGB and phenology coming from a longterm experiment, located in Apulia region. The calibration was performed using data collected in the period 1978-1990; validation was carried out on the 1991-2009 data. Phenology simulation was sufficiently accurate, showing some limitation only in predicting the physiological maturity. Yields and AGBs were predicted with an acceptable accuracy during both calibration and validation. CRM resulted always close to optimum value, EF in every case scored positive value, the value of index $\mathrm{r}^{2}$ was good, although in some cases values lower than
\end{abstract}

Correspondence: Dr. Ettore Bernardoni, Università di Milano, Dipartimento di Produzione Vegetale, via Celoria 2, 20133 Milano, Italy.

Tel. +39.02.50316598 - Fax: +39.02 .50316521 .

E-mail: ettore.bernardoni@unimi.it

Key words: climate change, grain production, cropping system, downscaling process.

Acknowledgements: this research was funded by CLIMESCO Evolution of cropping systems as affected by climate change project, contract n. 285, 20/02/2006 (Ministry for Education, University and Research).

Received for publication: 19 July 2011.

Accepted for publication: 2 November 2011.

(C) Copyright E. Bernardoni et al., 2012

Licensee PAGEPress, Italy

Italian Journal of Agronomy 2012; 7:e13

doi:10.4081/ija.2012.e13

This article is distributed under the terms of the Creative Commons Attribution Noncommercial License (by-nc 3.0) which permits any noncommercial use, distribution, and reproduction in any medium, provided the original author(s) and source are credited.
0.6 were calculated. Slope of the linear regression equation between measured and simulated values was always close to 1, indicating an overall good performance of the model. Both future climate scenarios led to a general increase in yields but a slightly decrease in AGB values. Data showed variations in the total production and yield among the different periods due to the climate variation. TOC evolution suggests that the combination of temperature and precipitation is the main factor affecting TOC variation under future scenarios. Incorporation of crop residues had a positive effect, in the first $35 \mathrm{~cm}$ the amount of carbon increase with both the future scenarios.

\section{Introduction}

The fourth assessment report AR4 of the Intergovernal Panel on Climate Change (IPCC), published in 2007, stated: Warming of the climate system is unequivocal, as is now evident from observations of increases in global average air and ocean temperatures, widespread melting of snow and ice, and rising mean sea level.

The key question is how the climate change may have impact on agriculture. The impact of future climate change on crop production has been widely studied using crop models and climate change scenarios (Tubiello et al., 2000; Ventrella et al., 2009; Richter et al., 2010). Future climate scenarios may be beneficial in some region, but could reduce productivity in zones where optimal conditions of temperature already exists (Ortiz et al., 2008).

Durum wheat (Triticum turgidum L. subsp. durum) is the most cultivated autumn-sown crop in Italy, in rain-fed condition. In 2010 about 1.3 million hectares were sown in Italy, approximately 283.000 of it in Apulia region (ISTAT, 2010). Its importance and the great uncertainty related to the possible effects of climate change, reveal the necessity of researches aimed at understanding the impact of global warming for wheat productions in Mediterranean regions. Furthermore, the crop productivity is directly related to soil quality (Doran et al., 1994) and total organic carbon is traditionally used as an indicator of soil quality (Doran and Parkin, 1994). Cereal straw is mainly returned to the soil in Mediterranean arable cropping systems (Saffih-Hdadi and Mary, 2008) and represents the major source of soil carbon where organic fertilizers are not applied. Nevertheless, little information is available on soil carbon dynamics under climate change scenarios. To explore future scenarios for agricultural systems management, the importance of simulation models is well recognized (Tubiello, 1999; Ferrara et al., 2010), because they are useful tools to organize knowledge and test scientific hypothesis (Donatelli et al., 2002).

The software used in this work is a hybrid dynamic deterministic model able to simulate, under different pedoclimatic conditions, the processes involved in cropping system such as crop growth and development and water and nitrogen balance. It implements different approaches, in order to ensure accurate simulation of any process 
related to soil-crop-atmosphere continuum, through the hybridization of existing models. An hybrid model is a modelling solution implementing single process models linked together in order to build a new simulation system (Bregaglio et al., In press).

The object of this study was to calibrate a hybrid model in a Mediterranean cropping system, using data from a long-term experiment, and to simulate the impact of future climate change scenarios on crop productivity and soil organic carbon dynamics.

\section{Materials and methods}

\section{The model}

This software is a crop nitrogen and carbon simulation model with daily time-step, able to estimate the water dynamics in soil, and to simulate nitrogen plant uptake, soil nitrogen dynamics and carbon cycle.

The software was written with an object-oriented language, Visual Basic 6.0, using UML (Unified Modelling Language, Rumbaugh et al., 2005; Ferrara and Rana, 2006) and the object structure is produced directly from the UML representation. The model simulates: i) agrometeorological variables, with a micro-meteorological model that simulates the energy balance, allowing for evapotranspiration estimation; ii) crop development and growth with a crop development and growth model based on a School of de Wit (van Ittersum et al., 2003) such as SUCROS (Van Keulen et al., 1982) and the derived WOFOST (Van Keulen and Wolf, 1986; Boogaard et al., 1998), for the $\mathrm{CO}_{2}$ assimilation, that uses global radiation and temperature and on the basis of STAMINA model (Richter et al., 2006; 2010; Acutis et al., 2007); iii) the soil water balance with an hydrological model that can be alternatively chosen as a physically based approach (Richards equation, Richards, 1931), or the empirical cascading approach (Burns et al.,
1974); iv) the nitrogen and carbon balance simulation is based on SOILN (Eckersten et al., 1996; Larsson et al.,1999) and LEACHM (Hutson, 2003) models. Figure 1 shows the logical structure of nitrogen and carbon balance.

Crop development stages are defined in terms of generalised decimal scale (Biologische Bundesanstalt, Bundessortenamt and Chemical industry - BBCH; Lancashire et al., 1991; Stauss, 1994; Meier, 2001) and the model allows user-defined parameters for thermal time to reach specific phenological stage. Between two stages, coefficient are linearly interpolated according to the BBCH stage reached. The user can also choose the approach to calculate evapotranspiration between the Penman-Monteith (Monteith, 1965) or the Priestley-Taylor (Priestley and Taylor, 1972) methods. The user can also define the crop type, sowing and harvest time, amount, type and time of nitrogen fertilizer applications, time and amount of irrigation events. The software uses three categories of organic pool (humus, manure and litter), each characterized by its own rate of mineralization or transformation. Both manure and litter pools can be immobilized in the humus pool. In SOILN only three pools of organic nitrogen are simulated: humus, litter, manure, whereas, in this software, each type of organic matter has been differentiated with reference to mineralisation rates, respiration losses and $\mathrm{C} / \mathrm{N}$ ratio, allowing for separate calculations for the different types of organic fertilisers or crop residuals incorporated into the soil. Depth of incorporation is also taken in account. Especially for residuals, the crop is divided in four parts, leaves, stems, storage organs and roots. The user can indicate the percentage of the crop part incorporated, as well the mineralization rate, the carbon fraction and the $\mathrm{C} / \mathrm{N}$ of every part.The mineralization rate is affected by temperature, moisture and $\mathrm{C} / \mathrm{N}$ ratio.

\section{Experimental data and site description}

Weather, soil and crop data for the calibration and validation, came from a study carried out on a silty clay soil (clay, 41.3\%; silt, $41.3 \%$;

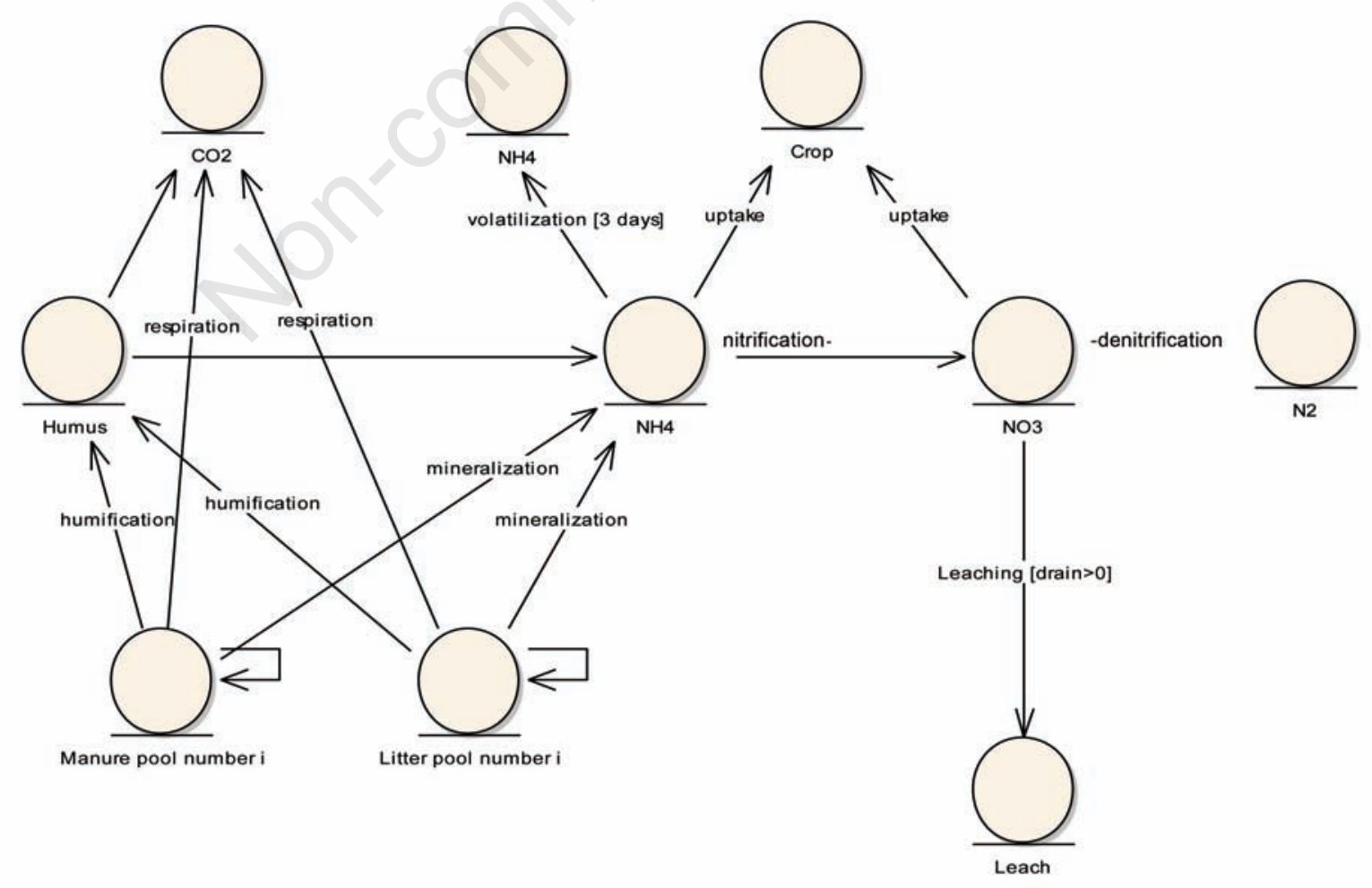

Figure 1. Logical structure of nitrogen and carbon balance, according to UML representation. 
erate scenario due to mitigation measures, with a global warming $+2.4^{\circ} \mathrm{C}$ (uncertainty ranges $1.4-3.8^{\circ} \mathrm{C}$ ). More details about description for these scenarios are available in Pizzigalli et al. (2012). Colturali degli Ambienti caldo-aridi (CRA-SCA) located in Foggia, (Apulia Tavoliere), in Southern Italy. Since 1978, the experimental field was managed to investigate the effects of nine different treatments of durum wheat crop residues management, using a randomized block schemes with 5 replicates for each treatment, with $80 \mathrm{~m}^{2}$ elementary plots. In this work we selected a treatment where all postharvest crop residues were subjected to incorporation and $100 \mathrm{~kg}$ $\mathrm{NH}_{4} \mathrm{NO}_{3}$ ha $^{-1}$ was applied, according to conventional practices in the region, during the plant growth cycle (top dressing) at the $5^{\text {th }}-6^{\text {th }}$ leaf stage. Daily maximum and minimum temperature, solar radiation and precipitation were recorded at the agro-meteorological station Podere 124. The data set covers the period from January 1977 to December 2009. More details about description for this station and data are available in Vitale et al. (2010). Before the calibration, a quality data check was performed. In particular, for radiation we use the Iqbal (1983) approach, used also in Bechini et al. (2000) for the data check. The atmospheric transmissivity $(T)$ was calculated, for every year, by averaging the five highest $\mathrm{T}$ between day of year (DOY) 120 and DOY 240. Years with $T<0.71$ have been considered affected by instrumental errors (Bechini et al. 2000). For these years, with $\mathrm{T}$ too low, solar radiation was estimated using the Donatelli and Campbell approach (Donatelli and Campbell,1998) using the parameters proposed for the software RadEst (Donatelli et al., 2003), for the Foggia location.

\section{Calibration of the model}

The experimental data used were not specifically collected for the calibration and validation of simulation models; hence some variables of interest were lacking (leaf area index, soil nitrogen content, soil water content, soil organic matter) and were not available for the entire period. However, the model was calibrated using phenological and production data (yield and aboveground biomass, AGB), as shown in Figure 2. Growing degree days (GDD) for the main development stages were calculated as the average of the GDD cumulated in each year to reach the stages defined, to obtain the values in Table 1 . The calibration was performed for the period 1978-1990, whereas data collected from 1991 to 2009 were used for validation, following the datasplitting procedure proposed by Power (1993). Model evaluations are usually performed by simulating only isolated growing seasons, whereas the ability of a cropping system simulation model to predict yields for a continuous period of several years is best shown with long time calibration and validation periods (Donatelli et al., 1997). To do a long time calibration, we assumed that a set of parameters may be representative of a group of varieties, with a procedure similar to that carried out by Confalonieri et al. (2009) for rice. Also for the future scenario simulation, we assumed that no new variety will be introduced.

\section{Climatic change projection}

We chose three time horizon for climatic change projection: I represent the climatic change for the period 2011-2040; II represent the climatic change projection for the period 2041-2070 and III represent climatic change projection for the period 2071-2100. Daily data for these periods were obtained from climatic projection generated using the HadCM3 (Gordon et al., 2000) general circulation models (GCM) of Hadley Centre Met Office (UK), and by a statistical downscaling process for the study area (Pizzigalli et al., 2012). Two emission scenarios (ES) were chosen among those indicated in the Fourth Assessment Report of the Intergovernmental Panel on Climate Change (IPPC, 2007): A2, a marked climate change with global warming of $+3.4^{\circ} \mathrm{C}$ by 2100 (uncertainty ranges $2.0-5.4^{\circ} \mathrm{C}$ ), and $\mathrm{B} 1$, a mod-

\section{Results and discussion}

\section{Calibration and validation}

\section{Crop phenology}

The predicted lengths in days for the periods: sowing - emergency, emergency - stem elongation, stem elongation - heading and heading - physiological maturity are plotted $v s$ the observed data in Figure 3.

In general, the greatest error was associated with the prediction of the physiological maturity date. In wheat, there are no simple early visual morphological signs strongly correlated, for a wide range of environmental conditions, with the cessation of kernel dry matter accumulation (Calderini et al., 2000), therefore, in the field, it is not easy to establish the exact day of physiological maturity, so it is impossible to separate the model error from the measurement error.

\section{Crop yield and aboveground biomass}

The agreement between observed and simulated values was expressed by the indexes proposed by Loague and Green (1991) and more recently discussed by Fila et al. (2003) and Confalonieri et al. (2009): the simulation bias (E), the relative root mean squared error

Table 1. Mean of growing degree days used for the calibration of the model for every phenological stage.

\begin{tabular}{lcc} 
Phase & GDD ${ }^{\circ} \mathrm{C}$ & SD \\
Sowing-emergency $(0-9)^{*}$ & 232 & 2.3 \\
Emergency-stem elongation $(9-30)^{*}$ & 858 & 3.5 \\
\hline Stem elongation-heading $(30-51)^{*}$ & 392 & 3.1 \\
Heading-physiological maturity (51-82)* & 829 & 2.7 \\
\hline
\end{tabular}

GDD, growing degree days; *BBCH identification keys
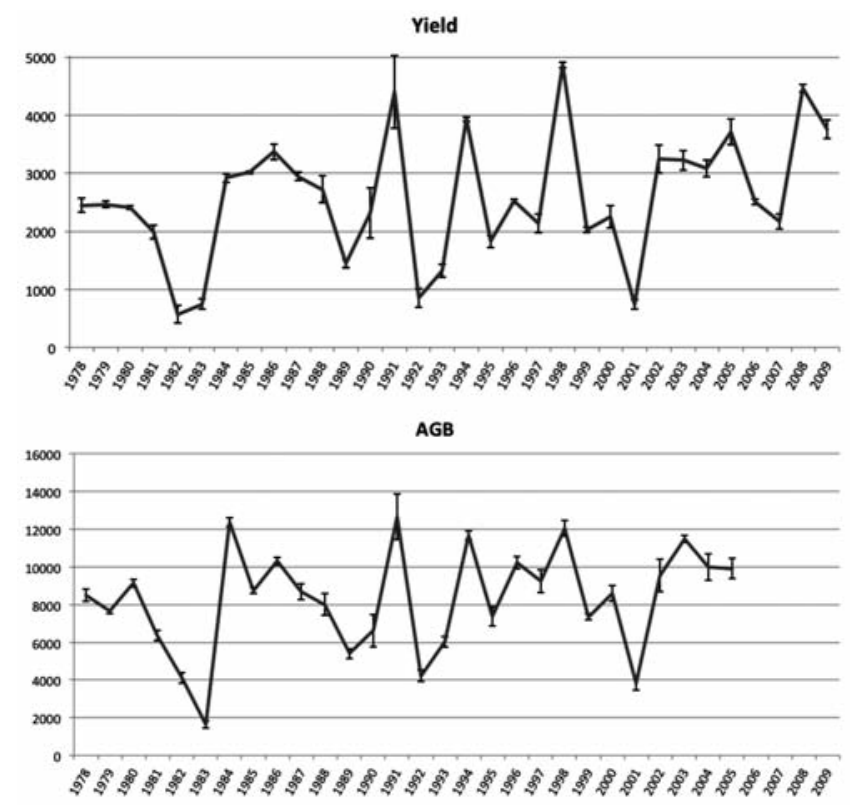

Figure 2. Wheat yield $\left(\mathrm{kg} \mathrm{m}^{-2}\right)$ and above ground biomass (AGB, $\mathrm{kg} \mathrm{m}^{-2}$ ) and their standard deviation for the experimental field. 
(RRMSE), the slope of the 0-M regression line, the coefficient of determination $\left(\mathrm{r}^{2}\right)$, the modelling efficiency (EF) and the coefficient of residual mass (CRM); Figure 4 reports the results for the process of calibration $(\mathrm{a}, \mathrm{b})$ and validation $(\mathrm{c}, \mathrm{d})$.

Yields and AGB were predicted with an acceptable accuracy in both
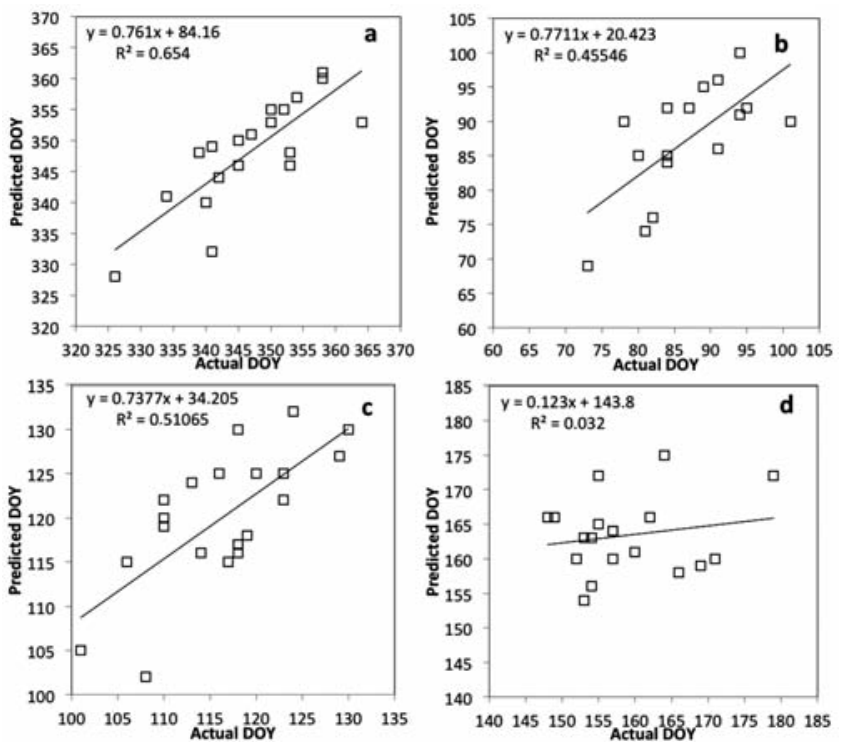

Figure 3. Regression between predicted lengths in days for the periods: a) sowing - emergency; b) emergency - stem elongation; c) stem elongation - heading; d) heading - physiological maturity.
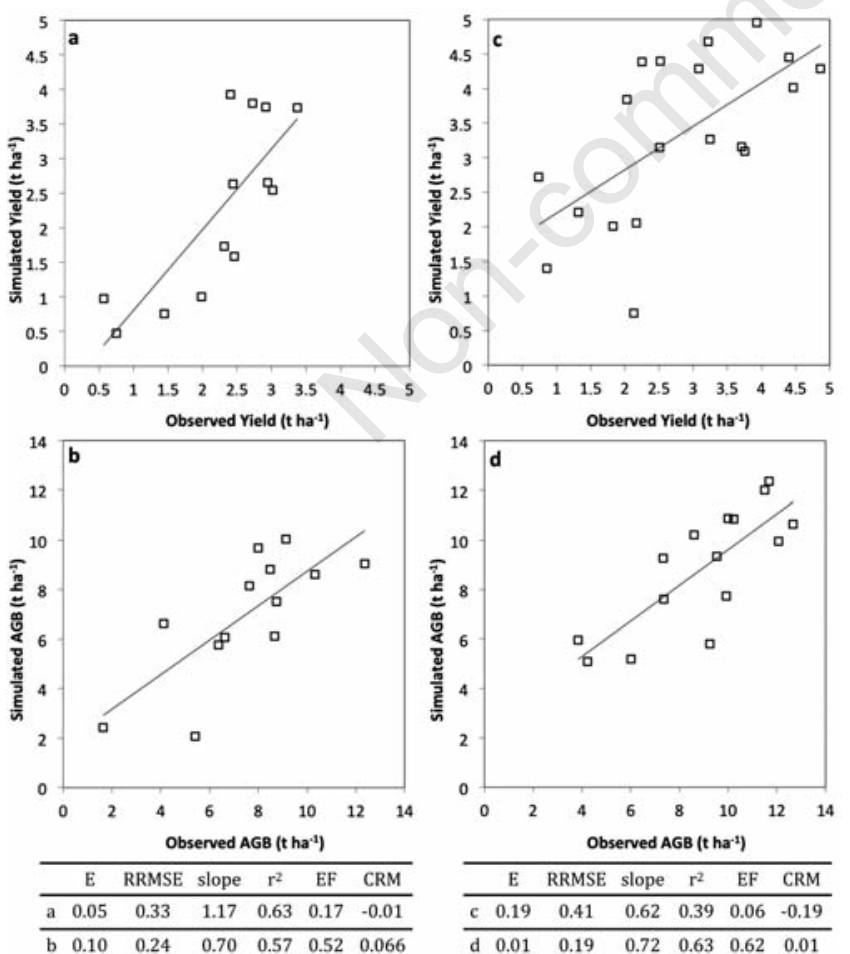

Figure 4. Regression between observed and simulated grain yield and aboveground biomass (AGB) for calibration process $(a, b)$ and validation $(c, d)$ and relative indices of agreement. calibration and validation processes. The model performance indices, such as RRMSE and E, indicated an overall satisfactory model accuracy. CRM resulted always close to the optimum, EF in every case scored positive value, the value of index $r^{2}$ was usually good, although in some cases values lower than 0.6 were obtained. In particular, $\mathrm{r}^{2}$ of the yield validation process had the lowest value, scoring 0.39 due to the general overestimation of the yield (CRM value slightly negative, -0.19). In the 1997, 2000 and 2001 years, the high CV of the field measurements, probably due to errors in measuring yield or in high variation in the experimental plots, could explain the lower performance of the model in simulating yield. Slope values were always close to 1 , indicating an overall good performance of the model, also in the cases discussed above.

A study performed by Donatelli et al. (1997) showed limitations in predicting yield only for durum wheat grown at Foggia. In that case, the CropSyst model results were not satisfactory, with worst outcome.

An accurate modelling of crop yield and total aboveground biomass is a prerequisite to quantify carbon additions as residues and their subsequent transformations in the soil (Izaurralde et al., 2006).

\section{Climate change and effect on production}

Simulation results showed variations in the total production and yield among the different time frames (Figure 5).

For B1 scenario, we noted a general increase in yields but a slightly decrease of the AGB values. We obtained an increase of about $15 \%$ for the I period, $11 \%$ for II period and $26 \%$ for the III period. Conversely, for the same scenarios, we observed a reduction in AGB of $5 \%$ and $2 \%$, respectively, for the I and II period, and a slight increase (5\%) for the III period.

Also for the A2 scenario, an increase in yields was simulated. In this cases we noted an increase of $17 \%$ and $23 \%$ for the I and II period and a smaller increase (8\%) in yields for the III period. Also the results with the AGB production are different, with a very slight increase for the I and II period ( $1 \%$ and $0.5 \%$ ) and a decrease of about $5 \%$ in the III period. Temperature increases are expected to reduce the length of the growing season as a whole, as well as the grain filling period, but our data suggest that it could have a positive effect. The estimated reduction in length of the growing season, probably allows wheat to partially escape form the drought during grain formation and filling. Projected climate change simulated by HadCM3 determined an increase in yields for all the scenarios. This was the effect of the higher amount of rain, predicted by the HadCM3 model, combined with rising temperatures. Results reported in literature are comparable. Zhang and Nearing (2005), Mo et al. (2009), Guo et al. (2010), Farina et al. (2011), using the same climate change scenario,

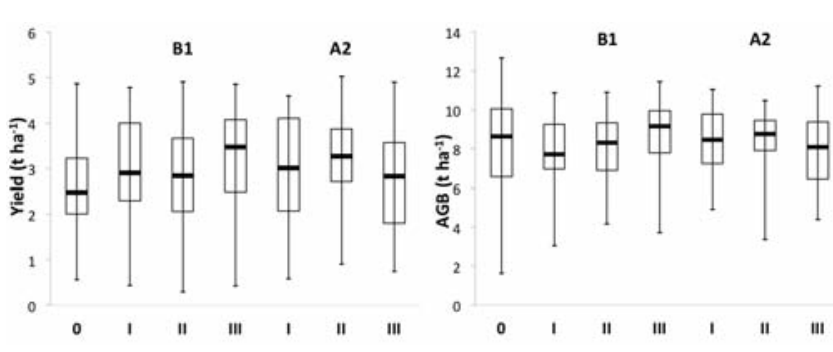

Figure 5. Changing in crop yield and aboveground biomass under climate change projection; $O$ represent the observed data for the period 1978-2009 (1978-2005 for aboveground biomass), I represent the results under climatic change for the period 2011-2040, II the results under climatic change for the period 2041-2070 and III the results under climatic change projection for the period 20712100, for both scenarios B1 e A2. 
in different region with different simulation model, found a general increase in yields for wheat. Also reducing the length of the growing season would reduce the crop water requirements and that should reduce the water stress under rain-fed conditions. Rising temperatures led to reach the various phenological stages in less time. We noted, for the entire period and for both scenarios, a decreasing trend in the length of the growing season (about five days).
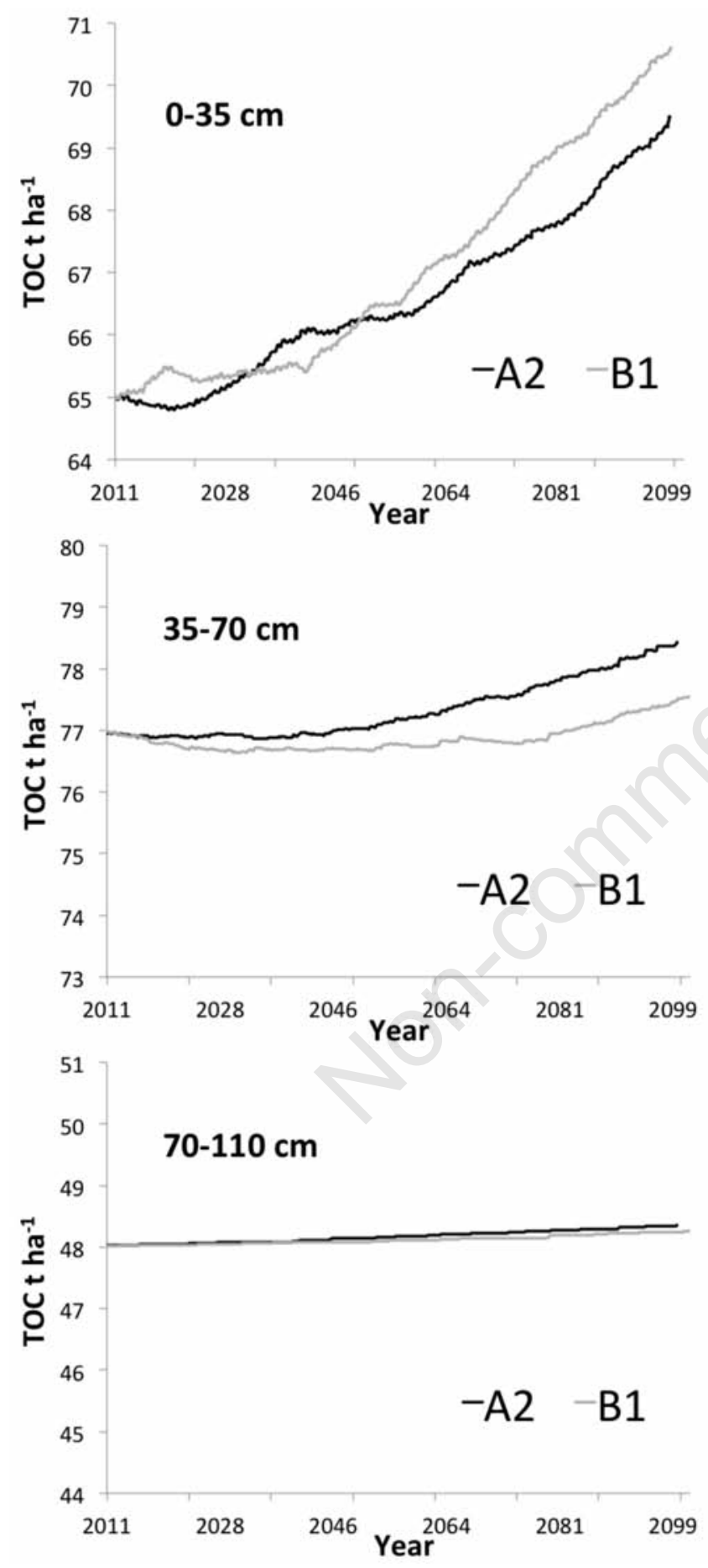

Figure 6. Simulated total organic carbon in soil under climate change.

\section{Climate change and effect on soil carbon}

The issue of soil carbon sequestration is of special interest in Mediterranean areas, (Farina et al., 2011) where soil organic carbon is, in general low, due to climatic condition and agricultural practices. Even if no data for making a calibration of the parameters involved with the evolution of soil organic carbon were available, we show the results of the simulation as a demonstration of the potentiality of the software. Figure 6 shows the evolution of TOC for both the climate scenarios. Initial TOC derive from analysis, and represent an input for the model initialization. At the end of the simulated period, we noted a general increase of TOC for both scenarios. However, in the first $35 \mathrm{~cm}$, the amount of carbon increases in both scenarios due to the incorporation of crop residues. The lower increases in average temperature in $\mathrm{B} 1$ advantage the soil carbon accumulation compared to A2 scenario at the end of the period where biological activity is supposed to be more intense. The shape of the curve from 2011 to 2050 , showed that this phenomenon varies along years: from 2011 to 2040 both scenarios had the same mean temperature (approximately $21.8^{\circ} \mathrm{C}$ ), but from 2011 to 2018 the $\mathrm{A} 2$ scenario shows more abundant precipitation (498 $\mathrm{mm}$ in $\mathrm{B} 1,633 \mathrm{~mm}$ in $\mathrm{A} 2$ ) that promotes the mineralization rate. In this first phase, we noted a decrease in TOC in the scenario Al. From 2018 to 2040 mean rainfall presented the same values for both scenarios, but the reduction in AGB in B1 allowed a higher TOC accumulation for the A2 scenario. After this period, higher temperatures in $\mathrm{A} 2$ associated to a greatest AGB production in $\mathrm{B} 1$ allowed a higher TOC accumulation in B1. From 35 to $70 \mathrm{~cm}$ we found little variations in TOC. At this depth the influence of temperature is very limited; the only source of carbon came from roots. The root biomass is related to the AGB, and the variation of AGB discussed before, explains the variation of TOC in this part of the profile. After $70 \mathrm{~cm}$, variations close to zero were registered. At this depth, the only source of organic materials is solely from crop root residues, and the loss of soil organic carbon is very small due to the slow decomposition.

\section{Conclusions}

We tested the capability of our model to simulate durum wheat in Mediterranean environment under rain-fed conditions. The software could reasonably well simulate the cropping system, although more detailed data set is needed for this type of software that uses a high number of parameters. The effects of future climate change in a durum wheat monoculture are also investigated using this software. There are sources of uncertain in this work that ought to be considered. First of all, we use fixed $\left(\mathrm{CO}_{2}\right)$ values, while the concentration is expected to increase. Another cause of uncertainty is that we used the same parameter set, assuming that new varieties will not be introduced. Nevertheless, our simulations predict an increase in yields, comparable to other studies, due to rising temperature and high amount of rain, predicted by the HadCM3 model. Simulated TOC evolution show that the incorporation of straw could be a key practice to improve the amount of carbon in soils, also under monoculture of wheat. However, the evaluation of the effects of straws incorporation on the spread of pathogens and disease still needs to be assessed.

\section{References}

Acutis M, Rana G, Trevisiol P, Bechini L, Laudato M, Ferrara RM, Richter GM, 2007. Integrating a spatial micrometeorological model into the risk assessment for arable crops in hilly terrain. 
In: K.C. Kersebaum, J.M. Hecker, W. Mirschel and M. Wegehenkel (eds.) Modelling water and nutrient dynamics in soil-crop systems. Springer Ed., Dordrecht, The Netherlands, pp 51-57.

Bechini L, Ducco G, Donatelli M, Stein A, 2000. Modelling, interpolation and stochastic simulation in space and time of global solar radiation. Agr. Ecosyst. Environ. 81:29-42.

Boogaard HL, van Diepen CA, Rötter RP, Cabrera JCMA, van Laar HH, 1998. WOFOST 7.1 User guide for the WOFOST 7.1 crop growth simulation model and WOFOST Control Center 5.1, Technical Document No. 52. Alterra WUR Publ., Wageningen, The Netherlands.

Bregaglio S, Confalonieri R, Donatelli M, Perego A, Giussani A, Alfieri L, De Mascellis R, Bonfante A, Basile A, Acutis M, 2011. Evaluating modelling solutions for soil temperature simulation. Environ. Modell. Softw. (In press).

Burns IG, 1974. Model for predicting redistribution of salts applied to fallow soils after excess rainfall or evaporation. J. Soil Sci. 25:165-178.

Calderini DF, Abeledo LG, Slafer GA, 2000. Physiological maturity in wheat based on kernel water and dry matter. Agron. J. 92:895-901.

Confalonieri R, Acutis M, Bellocchi G, Donatelli M, 2009. Multi-metric evaluation of the models WARM, CropSyst, and WOFOST for rice. Ecol. Model. 220:1395-1410.

Donatelli M, Bellocchi G, Fontana F, 2003. RadEst 3.00: software to estimate daily radiation data from commonly available meteorological variables. Eur. J. Agron. 18:363-367.

Donatelli M, Campbell GS, 1998. A simple model to estimate global solar radiation. pp 133-134 in Proc. 5th Congr. European Society for Agronomy, Nitra, Slovakia.

Donatelli M, Stöckle C0, Ceotto E, Rinaldi M, 1997. Evaluation of CropSyst for cropping systems at two locations of northern and southern Italy. Eur. J. Agron. 6:35-45.

Donatelli M, Tubiello FN, Peruch U, Rosenzweig C, 2002. Impacts of climate change and elevated $\mathrm{CO} 2$ on sugar beet production in northern and central Italy. Ital. J. Agron. 6:133-142.

Doran JW, Parkin TB, 1994. Defining and assessing soil quality. In: J.W. Doran, D.C. Coleman, D.F. Bezdicek and B.A. Stewart (eds.) Defining soil quality for a sustainable environment. SSSA Publ., Madison, WI, USA, pp 3-21.

Doran JW, Sarrantonio M, Janke R, 1994. Strategies to promote soil quality and health. Proc. OECD Co-operative Research project on Biological Resource Management 1:230-237.

Eckersten H, Janssson PE, Johnsson H, 1996. SOILN model, user's manual, third edition. Communication no. 96:1. Swedish University of Agricultural Sciences Publ., Uppsala, Sweden.

Farina R, Seddaiu G, Orsini R, Steglich E, Roggero PP, Francaviglia R, 2011. Soil carbon dynamics and crop productivity as influenced by climate change in a rainfed cereal system under contrasting tillage using EPIC. Soil Till. Res. 112:36-46.

Ferrara RM, Rana G, 2006. Application of the unified modelling language to a spatially distributed micrometeorological model at catchement scale. Riv. Ital. Agrometeorol. 1:32-40.

Ferrara RM, Trevisiol P, Acutis M, Rana G, Richter GM, Baggaley N, 2010. Topographic impacts on wheat yields under climate change: two contrasted case studies in Europe. Theor. Appl. Climatol. 99:53-65.

Fila G, Bellocchi G, Acutis M, Donatelli M,. 2003. IRENE: a software to evaluate model performance. Eur. J. Agron. 18:369-372.

Gordon C, Cooper C, Senior CA, Banks H, Gregory JM, Johns TC, Mitchell JFB, Wood RA, 2000. The simulation of SST, sea ice extents and ocean heat transports in a version of the Hadley Centre coupled model without flux adjustments. Clim. Dynam. $16: 147-168$.

Guo R, Lin Z, Mo X, Yang C, 2010. Responses of crop yield and water use efficiency to climate change in the North China Plain. Agr. Water Manage. 97:1185-1194.

Hutson JL, 2003. LEACHM. Model description and user's guide. School of Chemistry, Physics and Earth Sciences. Flinders University of South Australia Publ., Adelaide, Australia.

Intergovernmental Panel on Climate Change, 2007. IPCC Fourth Assessment Report. Available from: http://www.ipcc.ch/

Iqbal M, 1983. An introduction to solar radiation. Academic Press, Toronto, ON, Canada.

Istituto Nazionale di Statistica, 2010. Dati annuali sulle coltivazioni. Available from: http://dati.istat.it/

Izaurralde RC, Williams JR, McGill WB, Rosenberg NJ, Jakas MCQ, 2006. Simulating soil C dynamics with EPIC. Model description and testing against long-term data. Ecol. Model. 192:362-384.

Larsson MH, Jarvis NJ, 1999. Evaluation of a dual-porosity model to predict field-scale solute transport in a macroporous soil. J. Hydrol. 215:153-171.

Lancashire PD, Bleiholder H, van den Boom T, Langelüddeke P, Stauss R, Weber E, Witzenberger A, 1991. An uniform decimal code for growth stages of crops and weeds. Ann. Appl. Biol. 119:561-601.

Loague K, Green RE, 1991. Statistical and graphical methods for evaluating solute transport models: overview and application. J. Contam. Hydrol. 7:51-73.

Meier U, 2001. Growth stages of mono- and dicotyledonous plants. BBCH Monograph, 2nd ed. Federal Biological Research Centre for Agriculture and Forestry Publ., Braunschweig, Germany, pp 14-16.

Mo XG, Liu SX, Lin ZH, Lin ZH, Guo RP, 2009. Regional crop yield, water consumption and water use efficiency and their responses to climate change in the North China Plain. Agr. Ecosyst. Environ. 134:67-78.

Monteith J, 1965. Climate and the efficiency of crop production in Britain. Philos. T. R. Soc. B 281:277-329.

Ortiz R, Sayre KD, Govaerts B, Gupta R, Subbarao GV, Ban T, Hodson D, Dixon JM, Ortiz MJI, Reynolds M, 2008. Climate change: Can wheat beat the heat? Agr. Ecosyst. Environ. 126:46-58.

Pizzigalli C, Palatella L, Zampieri M, Lionello P, Miglietta MM, Paradisi P, 2012. Dynamical and statistical downscaling of precipitation and temperature in a Mediterranean area. Ital. J. Agron. $7: \mathrm{e}$.

Power M, 1993. The predictive validation of ecological and environmental models. Ecol. Model. 68:33-50.

Priestley CHB, Taylor RJ, 1972. On the assessment of surface heat flux and evaporation using large-scale parameters. Mon. Weather Rev. 100:81-92.

Richards LA, 1931. Capillary conduction of liquids through porous medium. Physics 1:318-333.

Richter GM, Rana G, Ferrara RM, Ventrella D, Acutis M, Trevisiol P, Laudato M, Gusberti D, Mayer T, Baggeley N, Morris J, Holmes A, Trawick P, Dailey AG, Robbins P, Simota C, Whitmore AP, Powlson DS, 2006. Stability and mitigation of arable systems in hilly landscapes. Report to the European Commission, Brussels, Belgium.

Richter GM, Acutis M, Trevisiol P, Latiri K, Confalonieri R, 2010. Sensitivity analysis for a complex crop model applied to Durum wheat in the Mediterranean. Eur. J. Agron. 32:127-136.

Rumbaugh J, Jacobson I, Booch G, 2005. The Unified Modeling Language Reference Manual, 2nd ed. Addison Wesley Professional Ed., Boston, MA, USA.

Saffih-Hdadi K., Mary B. 2008. Modeling consequences of straw residues export on soil organic carbon. Soil Biol. Biochem. 40:594-607.

Stauss R, 1994. Compendium of growth stage identification keys for mono and dicotyledonous plants. Extended BBCH scale. CIBA Publ., Basel, Switzerland.

Tubiello FN, Donatelli M, Rosenzweig C, Stockle CO, 2000. Effects of 
climate change and elevated C02 on cropping systems: model predictions at two Italian locations. Eur. J. Agron. 13:179-189.

Tubiello FN, Rosenzweig C, Kimball BA, Pinter PJ Jr, Wall GW, Hunsaker DJ, Lamorte RL, Garcia RL, 1999. Testing CERES-Wheat with FACE data: CO2 and water interactions. Agron. J. 91:18561865.

van Ittersum M.K., Leffelaar P.A., Van Keulen H., Kropff M.J., Bastiaans L., Goudriaan J. 2003. On approaches and applications of the Wageningen crop models. Eur. J. Agron. 18:201-234.

Van Keulen H, Wolf J, 1986. Modelling of agricultural production: weather soils and crops. Simulation Monographs. Pudoc Ed., Wageningen, The Netherlands.

Van Keulen H, Penning de Vries FWT, Drees EM, 1982. A summary model for crop growth. In: F.W.T. Penning de Vries and H.H. Van Laar (eds.) Simulation of plant growth and crop production. Simulation Monographs. Pudoc Ed., Wageningen, The Netherlands, pp 87-98.

Ventrella D, Giglio L, Moriondo M, Bindi M, 2009. Vulnerability and adaptation to climate change of Sorghum cultivation in Southern Italy. IOP Conf. Ser. Earth Environ. Sci. 6:372048.

Vitale D, Rana G, Soldo P, 2010. Trends and extremes analysis of daily weather data from a site in the Capitanata Plain (Southern Italy). Ital. J. Agron. 5:133-143.

Zhang XC, Nearing MA, 2005. Impact of climate change on soil erosion, runoff, and wheat productivity in central Oklahoma. Catena 61:185-195. 